\title{
Potential deployment of offshore bottom pressure gauges and adoption of data assimilation for tsunami warning system in the western Mediterranean Sea
}

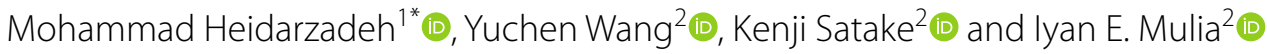

\begin{abstract}
Western Mediterranean Basin (WMB) is among tsunamigenic zones with numerous historical records of tsunami damage and deaths. Most recently, a moderate tsunami on 21 May 2003 offshore Algeria, North Africa, was a fresh call for strengthening tsunami warning capabilities in this enclosed water basin. Here, we propose to deploy offshore bottom pressure gauges (OBPGs) and to adopt the framework of a tsunami data assimilation (TDA) approach for providing timely tsunami forecasts. We demonstrate the potential enhancement of the tsunami warning system through the case study of the 2003 Algeria tsunami. Four scenarios of OBPG arrangements involving 10, 5, 3 and 2 gauges are considered. The offshore gauges are located at distances of 120-300 km from the North African coast. The warning lead times are 20, 30, 48 and 55 min for four points of interest considered in this study: Ibiza, Palma, Sant Antoni and Barcelona, respectively. The forecast accuracies are in the range of $69-85 \%$ for the four OBPG scenarios revealing acceptable accuracies for tsunami warnings. We conclude that installation of OBPGs in the WMB can be helpful for providing successful and timely tsunami forecasts. We note that the OBPG scenarios proposed in this study are applicable only for the case of the 2003 Algeria tsunami. Further studies including sensitivity analyses (e.g., number of OBPG stations; earthquake magnitude, strike, epicenter) are required in order to determine OBPG arrangements that could be useful for various earthquake scenarios in the WMB.
\end{abstract}

Keywords: Mediterranean Sea, Tsunami, Earthquake, Tsunami warning system, Offshore bottom pressure gauge, Tsunami data assimilation

\section{Introduction}

Western Mediterranean Basin (WMB) is a tsunamigenic zone within the Mediterranean Sea posing tsunami risks to Italy, France, Spain, Morocco, Algeria and Tunisia (Fig. 1). The region has experienced several tsunamis in the past; most recently on 21 May 2003 when a 2-m tsunami was generated following an Mw 6.9 earthquake offshore Algeria (Fig. 1) (Alasset et al. 2006; Sahal et al.

\footnotetext{
*Correspondence: mohammad.heidarzadeh@brunel.ac.uk

${ }^{1}$ Department of Civil \& Environmental Engineering, Brunel University London, Uxbridge UB8 3PH, UK

Full list of author information is available at the end of the article
}

2009; Heidarzadeh and Satake 2013). The tsunami was recorded on several tide gauges in the WMB including the four stations of Ibiza, Palma, Sant Antoni and Barcelona (Fig. 1). Other notable tsunamis in the WMB are: the 23 February 1887 event on the Ligurian Coast (Larroque et al. 2012; Eva and Rabinovich 1997) and the 21 August 1856 Djijelli (Algeria) tsunami (Roger and Hébert 2008) (stars in Fig. 1). Based on historical data of tsunami occurrences in the WMB, Soloviev (1990) identified four tsunamigenic zones in this basin namely: the coast of Spain (CoS), the North African Coast (NAC), the Ligurian Sea (LS) and the west coast of Italy and Tyrrhenian Sea (WCITS) (Fig. 1). Historical earthquake data 


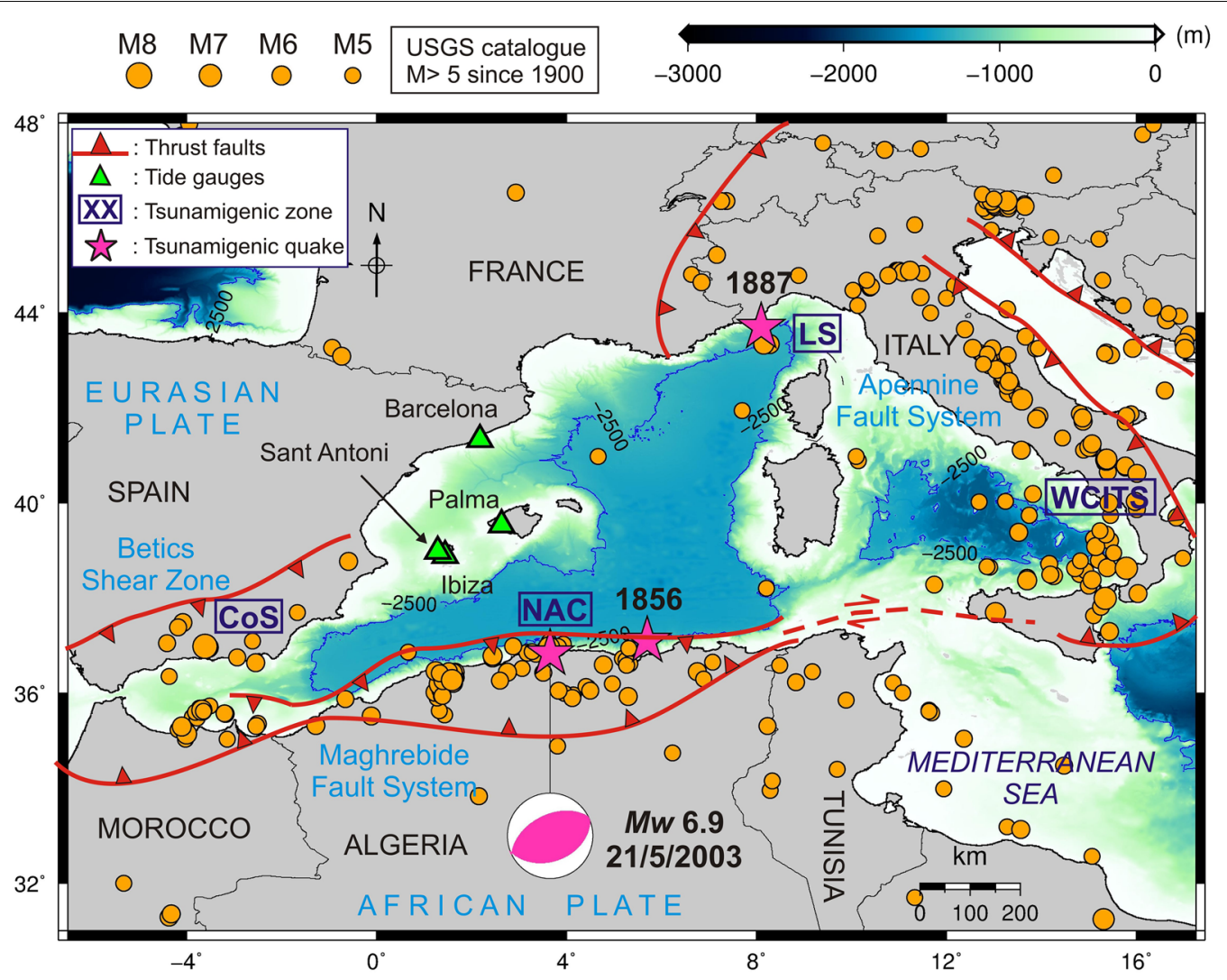

Fig. 1 The Western Mediterranean Basin (WMB) showing the epicenters of tsunamigenic earthquakes in May 2003 (offshore Algeria), 1887 and 1856 (their epicenters are shown by stars). Green triangles indicate locations of tide gauges. Four main tsunamigenic zones in the WMB (blue boxes) are shown based on the data from Soloviev (1990)

based on the United States Geological Survey's catalogue $(M>5)$ reveal that these four zones correspond to those with highest seismic activities within the WMB, in particular NAC and WCITS. The high seismic activity in this region is the result of the complicated tectonic boundaries between the African and Eurasian plates involving several micro-plates as well as multiple convergent and divergent plate boundaries (Fig. 1).

Due to such high seismicity and existing records of tsunami occurrences, tsunami warning systems have been developed for the Mediterranean basin in the framework of the NEAMTWS (North East Atlantic, Mediterranean and Connected seas Tsunami Warning System) since 2005 (Tinti et al. 2012; Papadopoulos and Fokaefs 2013; Papadopoulos 2015; IOC 2015; Necmioglu and Özel 2015; Necmioğlu 2016; Okal et al. 2009; Synolakis and Bernard 2006; Satake 2014). Starting from 2017, several countries (i.e., France, Greece, Italy, and Turkey) are equipped with national tsunami warning centers and act as Tsunami Service Providers (TSPs). Some other countries, including Portugal and Spain, will develop such capacities in the near future (Heidarzadeh et al.
2017). The performance of the Mediterranean TSPs has been tested during the 20 July 2017 Bodrum-Kos (Turkey-Greece) Mw 6.6 earthquake and tsunami revealing satisfactory response by three operational TSPs namely: CAT-INGV (Italy), KOERI-RETMC (Turkey), and NOA/ HL-NTWC (Greece) (Heidarzadeh et al. 2017; Dogan et al. 2019; Öztürk and Şahin 2019).

Although the response of the regional TSPs to the July 2017 event was assessed to be satisfactory, that moderate tsunami revealed that more investment should be devoted to the Mediterranean TSPs in two fronts: equipment for monitoring tsunamis and public education. In terms of equipment, Heidarzadeh et al. (2017) specifically pointed out the potential application of offshore tsunami gauges in the Mediterranean Sea. In the aftermath of the giant 2004 Indian Ocean tsunami, tens of offshore bottom pressure gauges (OBPGs) have been installed across the world oceans which are called DeepOcean Assessment and Reporting of Tsunamis (DART) (Gonzalez et al. 1998; Synolakis and Bernard 2006; Rabinovich and Eblé 2015; Heidarzadeh et al. 2015, 2016) which are spaced in the range of 400-4000 km from each 
other (Heidarzadeh and Gusman 2018). Two dense networks of OBPGs, called Seafloor Observation Network for Earthquakes and Tsunamis (S-net) and Dense Oceanfloor Network System for Earthquakes and Tsunamis (DONET), were deployed by the Japanese Government, with 150 gauges spaced approximately $30-50 \mathrm{~km}$ (Kanazawa 2013) for S-net and 51 gauges spaced $15-20 \mathrm{~km}$ for DONET (Kaneda et al. 2009, 2015). Such relatively dense offshore observation network provides the opportunity to use the real-time sea level data for tsunami forecast through tsunami data assimilation (TDA) (Maeda et al. 2015; Gusman et al. 2016; Wang et al. 2018). Although the TDA approach requires a relatively expensive network of OBPGs, it greatly improves the accuracy of tsunami forecasts.

The purpose of this study is to investigate whether a network of OBPGs can be effective for tsunami forecast in the WMB through a case study of the May 2003 earthquake and tsunami. Figure 2 provides tsunami travel time (TTT) analyses, using the software by Geoware (2011), for tsunamigenic earthquakes in two zones in the WMB namely the NAC (i.e., the 2003 tsunami in southern WMB) and LS (i.e., the 1887 tsunami in northern WMB) indicating that it takes approximately $70-80 \mathrm{~min}$ for the tsunami generated in each of these zones to arrive at the opposite coast in the WMB. Such relatively long TTT may imply that the WMB has the potential for application of TDA approach for tsunami forecast. We propose a hypothetical OBPG network and apply the TDA technique to investigate its effectiveness. A preliminary sensitivity analysis is performed to determine the performance of the system for different number of OBPGs.

\section{The May 2003 Algeria earthquake (Mw 6.9) and tsunami}

The 2003 Algeria earthquake was a thrust earthquake, with Mw 6.8-6.9 (Meghraoui et al. 2004; Déverchère et al. 2005) that occurred on 21 May at 18:44 UTC offshore north coast of Algeria (Fig. 3). The earthquake left more than 2000 deaths but the tsunami was moderate and no death was linked to the tsunami whose height was reported to be up to approximately $2 \mathrm{~m}$ (Alasset et al. 2006; Sahal et al. 2009). The tsunami waveform data used in this study include four tide gauge records in Ibiza, Palma, Sant Antoni and Barcelona with sampling intervals of 5, 1, 2 and $5 \mathrm{~min}$, respectively (Fig. 2). Detailed information about these tide gauges are presented in Heidarzadeh and Satake (2013). While sampling intervals of 1 and 2 min (Palma and Sant Antoni) relatively well allow recording of the tsunami signals, the sampling interval of 5 min (Ibiza and Barcelona) may not permit the full registration of the tsunami. It may be noted that most tide gauges worldwide were programmed for long sampling intervals of 5-15 min before the 2004 Indian Ocean tsunami. The sea level data used in this study are provided by UNESCO-IOC (Intergovernmental Oceanographic Commission), Puertos del Estado (Spain) (http://www. puertos.es/) and the European Sea Level Service.

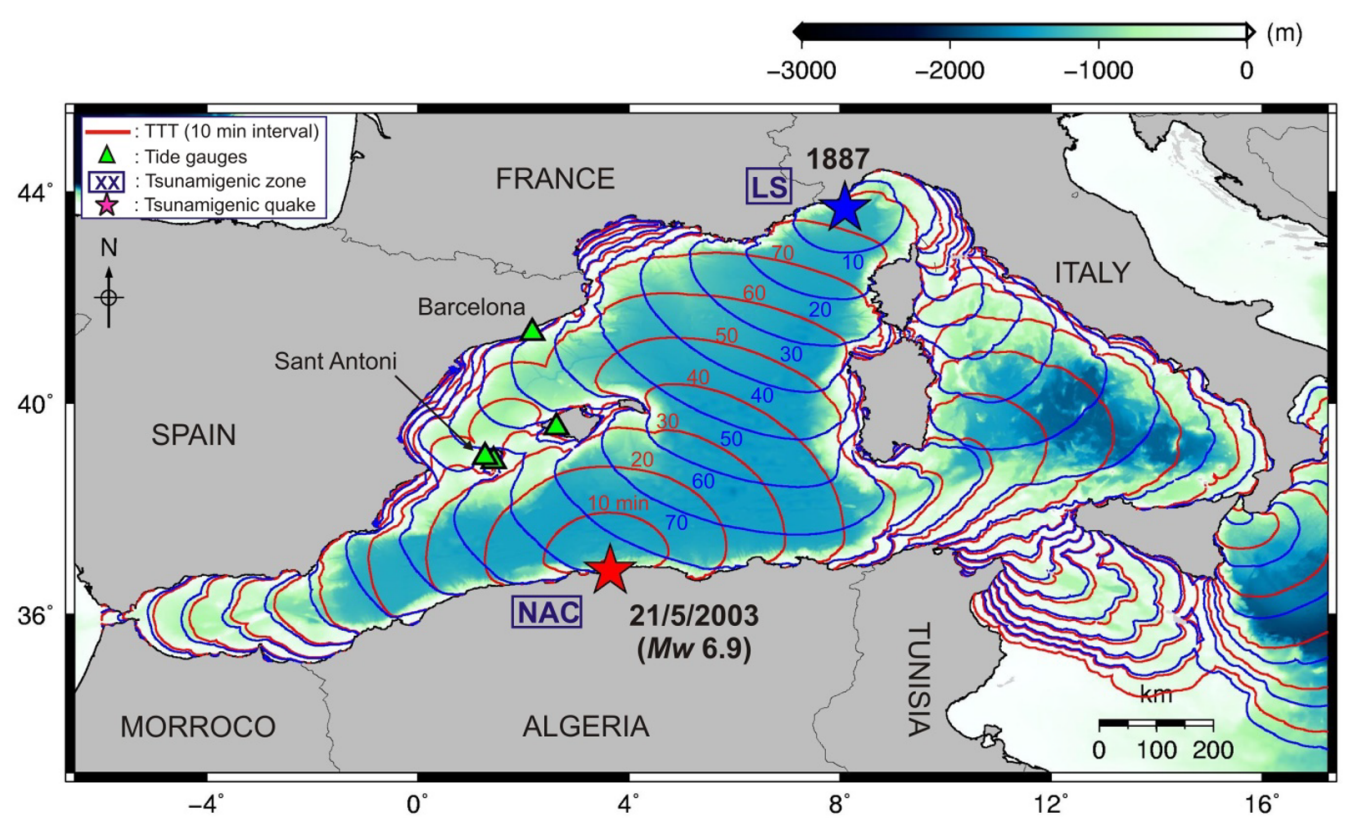

Fig. 2 Tsunami travel time (TTT) analysis for the 21 May 2003 (offshore Algeria) tsunami and the 1887 Ligurian Coast tsunami with contours of 10-min intervals 


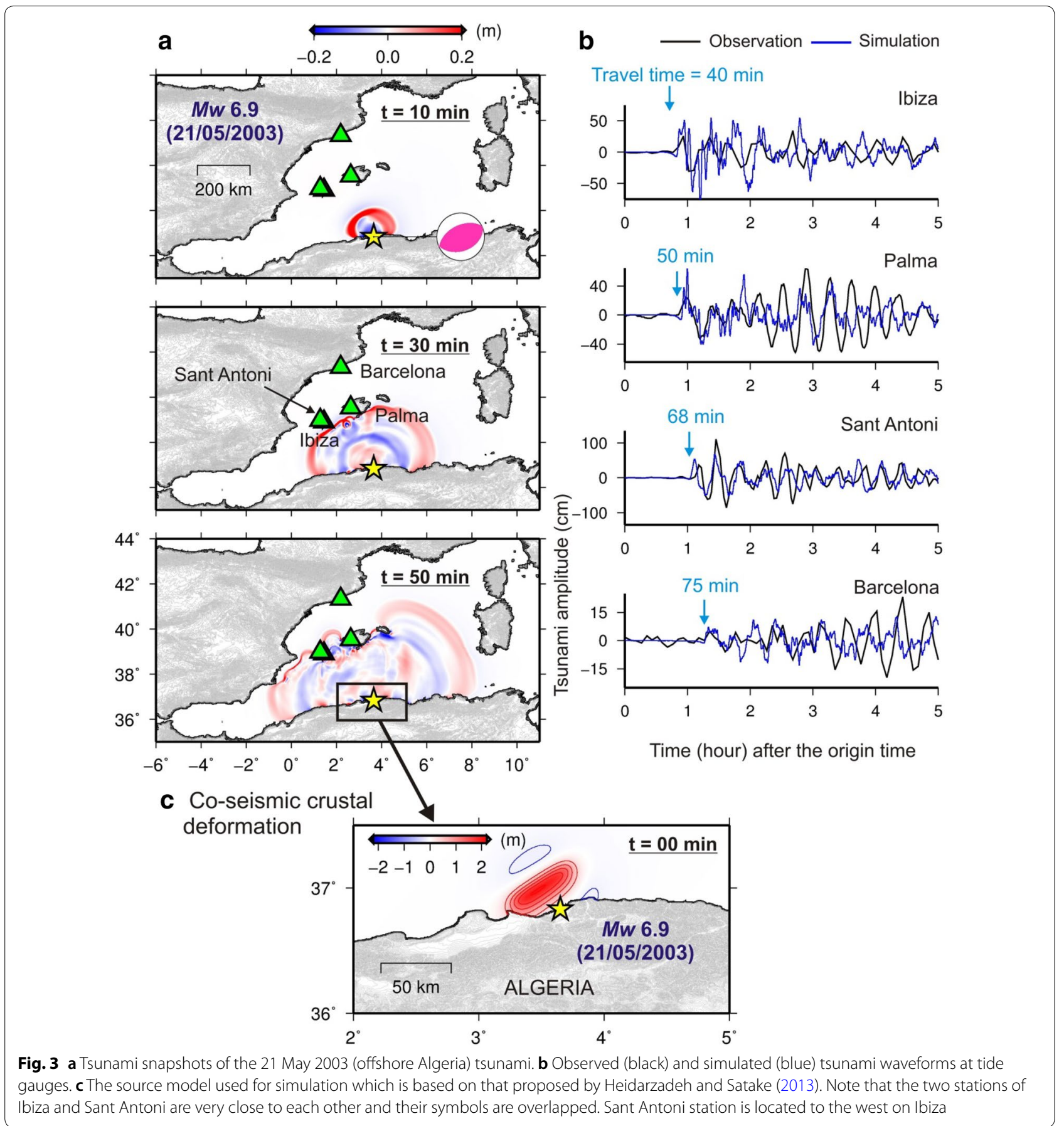

The tsunami recorded by tide gauges in the region (Fig. 3) show trough-to-crest wave heights of 59, 116, 196 and $43 \mathrm{~cm}$ in Ibiza, Palma, Sant Antoni and Barcelona, respectively (Heidarzadeh and Satake 2013). Note that the two stations of Ibiza and Sant Antoni, both in Ibiza island, are very close to each other and are overlapped in Fig. 3a; Sant Antoni station is located to the west of Ibiza. Based on the tide gauge data and TTT analysis, the tsunami arrived in Balearic Islands (Ibiza, Palma) after $\sim 40 \mathrm{~min}$, whereas it took $60-75 \mathrm{~min}$ for the waves to arrive at mainland France and Spain (Figs. 2, 3). The relatively long travel time of up to $75 \mathrm{~min}$ for tsunamis from the NAC zone to the coasts of Spain, France and other coasts in the WMB enables the application of TDA approach in a real-time tsunami forecast system. 


\section{Data and methods}

Bathymetry data are based on the 30 arc-sec grid of General Bathymetric Charts of the Oceans (GEBCO, Weatherall et al. 2015) which was interpolated to a 475 -m grid in this study. Forward tsunami modeling was conducted applying the Nonlinear Shallow Water tsunami model TUNAMI-N2 (Goto et al. 1997; Yalçiner et al. 2004) using a time step of $1.0 \mathrm{~s}$ and a total duration of $5 \mathrm{~h}$ for tsunami simulations on a single grid with Cartesian coordinate system. The tsunami source of the May 2003 event was based on that of Heidarzadeh and Satake (2013) having dimensions of $60 \mathrm{~km} \times 30 \mathrm{~km}$ and a uniform slip of $2 \mathrm{~m}$. The dislocation model of Okada (1985) was used to calculate the co-seismic crustal deformation as initial condition for tsunami propagation modeling. The software tsunami travel times (TTT) by Geoware (2011) was used for tsunami travel time analysis.

To examine the performance of OBPGs for tsunami forecast in the WMB through TDA approach, we consider a case study involving the NAC as the tsunamigenic zone and the May 2003 tsunami (Fig. 4) as a real tsunami event. We consider hypothetical OBPGs within the WMB and then investigate whether a TDA approach can benefit from them to provide timely tsunami forecasts for coasts of Spain and France in case a tsunami is generated from the NAC. Since an OBPG network is usually expensive in terms of installation and maintenance, it is important to design an efficient network with minimum number of OBPGs. Here, we considered four scenarios. The first scenario contains ten buoys (Fig. 4b) distributed at two rows with buoy spacing intervals of approximately $50 \mathrm{~km}$. The second scenario contains five buoys (Fig. 4c) by removing the northern row of the first scenario. The third and fourth scenarios contain three and two buoys, respectively, with spatial intervals of $\sim 100 \mathrm{~km}$ (Fig. 4d, e). The OBPGs in these four scenarios are distanced approximately $120-300 \mathrm{~km}$ from the North African coast.

For TDA, we adopted the optimal interpolation for tsunami data assimilation, because it has a relatively smaller computational cost than the ensemble Kalman filter (Maeda et al. 2015; Yang et al. 2019). This algorithm reconstructs the tsunami wavefield from the data of offshore tsunami observations through minimizing the total error of all the observations (Kalnay 2003). In the numerical simulation, we represent the tsunami wavefield at the $n$th time step as the vector $\boldsymbol{x}_{\boldsymbol{n}}$ defined as: $\boldsymbol{x}_{\boldsymbol{n}}=(h(n \Delta t, x, y), M(n \Delta t, x, y), N(n \Delta t, x, y))$, where $h$ is the tsunami height, $M$ and $N$ are depth-integrated flow discharge fluxes in two horizontal directions of $x$ and $y$. The offshore pressure gauges directly provide data of tsunami height, but the velocity components of $\boldsymbol{x}_{\boldsymbol{n}}$ are reconstructed during the assimilation process. The TDA approach is described by the following two equations (Maeda et al. 2015):

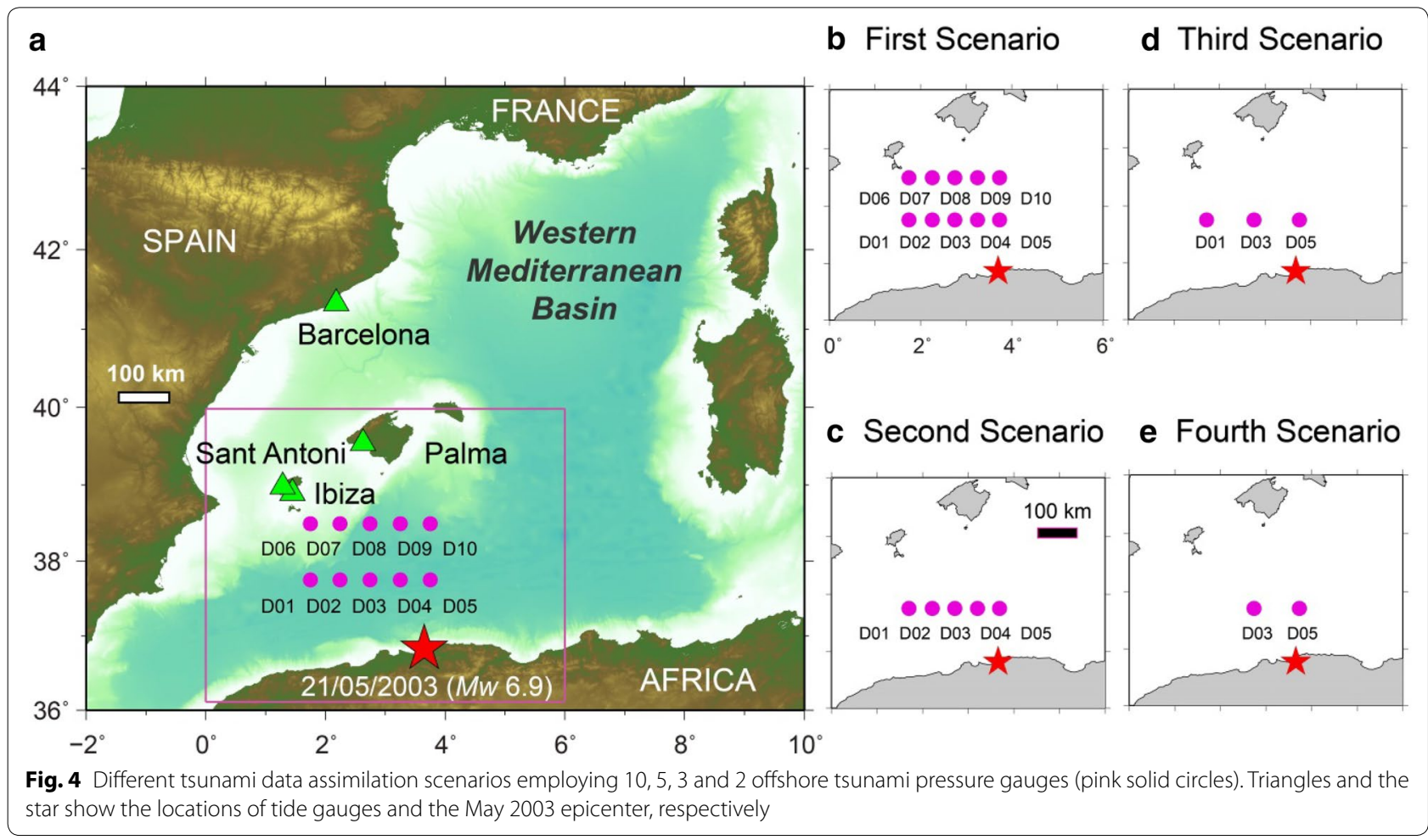




$$
\begin{aligned}
& \boldsymbol{x}_{n}^{\mathrm{f}}=\boldsymbol{F} \boldsymbol{x}_{n-1}^{a}, \\
& \boldsymbol{x}_{n}^{a}=\boldsymbol{x}_{n}^{\mathrm{f}}+\boldsymbol{W}\left(\boldsymbol{y}_{n}-\boldsymbol{H} \boldsymbol{x}_{n}^{\mathrm{f}}\right) .
\end{aligned}
$$

By using Eq. (1), we calculate the forecasted tsunami wavefield $\boldsymbol{x}_{n}^{\mathrm{f}}$ in time step $n$ from the assimilated tsunami wavefield at the previous time step $\boldsymbol{x}_{n-1}^{a}$. The matrix $\boldsymbol{F}$ is called the propagation matrix which corresponds to the tsunami propagation model. In Eq. (2), we assimilate the observed data in order to correct the forecasted tsunami wavefield. The observation matrix $\boldsymbol{H}$ is a sparse matrix, which contains only 0 and 1 values. It extracts the tsunami height from the forecasted wavefield, and calculates the residual with the real-time observed tsunami heights $\boldsymbol{y}_{n}$. Consequently, the residual is multiplied by the weight matrix $W$ to bring the assimilated wavefield closer to the real observation (Maeda et al. 2015; Gusman et al. 2016). To minimize the total error, we compute the weight matrix by solving the following linear system:

$$
\boldsymbol{W}\left(\boldsymbol{R}+\boldsymbol{H} \boldsymbol{P}^{\mathrm{f}} \boldsymbol{H}^{\mathrm{T}}\right)=\boldsymbol{P}^{\mathrm{f}} \boldsymbol{H}^{\mathrm{T}},
$$

where $\boldsymbol{P}^{\mathrm{f}}=\left\langle{ }_{\varepsilon}^{\mathrm{f}} \varepsilon^{\mathrm{fT}}\right\rangle$ and $\boldsymbol{R}=\left\langle\varepsilon^{\mathrm{O}}{ }_{\varepsilon}^{\mathrm{OT}}\right\rangle$ are the covariance matrices of the forward numerical simulation and the observations, respectively. $\varepsilon^{\mathrm{f}}$ and $\varepsilon^{\mathrm{O}}$ are the Gaussian errors associated with forward numerical simulations and observations, respectively, and $\varepsilon^{\mathrm{fT}}$ and $\varepsilon^{\mathrm{OT}}$ are the corresponding transpose matrixes. We assume that the computational errors are spatially homogeneous on numerical grids, and the observation errors are uncorrelated among stations because observations are made independently. These assumptions simplified the matrix $R$ into a diagonal matrix whose diagonal component was the standard deviation of the observation error at each station (Maeda et al. 2015). For both matrices, we assume a Gaussian-distributed covariance, with a characteristic distance of $20 \mathrm{~km}$ (Maeda et al. 2015; Wang et al. 2018). By repeatedly solving Eqs. (1) and (2) consequently, the tsunami wavefield is gradually assimilated, and the forecasted waveforms at any location inside the model domain can be obtained.

To evaluate the performance of the forecast, we selected four points of interest (PoIs) where actual tsunami observations from the May 2003 tsunami are available (i.e., Barcelona, Sant Antoni, Ibiza and Palma; Fig. 4a) and are used for waveform comparisons. We defined the time period during which the observational data are used for assimilation as the time window (Wang et al. 2017). A longer time window indicates that the tsunami passes through more OBPGs, and thus longer waveform data are assimilated. In this study, a time window of $20 \mathrm{~min}$, starting from the earthquake origin time, was used for
TDA (Fig. 5a). The waveforms in Fig. 5a are the results of forward simulations of the 2003 tsunami using the source model shown in Fig. 3c. As tsunami travel time from the source of the May 2003 tsunami to the nearest OBPG is approximately $7 \mathrm{~min}$ (Fig. 3), the time window of $20 \mathrm{~min}$ implies that $13 \mathrm{~min}$ of tsunami signals recorded on OBPGs will be used for assimilation. The time available to giving tsunami warnings to coastal areas, called as warning lead time, is the time interval between the end of the TDA and the tsunami arrival time (Fig. 5b).

The forecasted tsunami waveforms by the TDA are compared with simulated waveforms and observations at the PoIs. Both simulated and actual observation waveforms were used for forecast accuracy analysis in this study. To quantitatively analyze the accuracy of the forecasts, we applied a method for waveform comparisons by considering both the first-peak amplitude and the maximum amplitude of the tsunami, similar to the score of Tsushima et al. (2009) and the index of VRO of Yamamoto et al. (2016). Our method for waveform comparison applies the following equation:

$$
K=1-\frac{\sum\left(H_{\mathrm{f}}^{\max }-H_{\mathrm{o}}^{\max }\right)^{2}+\sum\left(H_{\mathrm{f}}^{\mathrm{arr}}-H_{\mathrm{o}}^{\mathrm{arr}}\right)^{2}}{\sum\left(H_{\mathrm{o}}^{\max }\right)^{2}+\sum\left(H_{\mathrm{o}}^{\mathrm{arr}}\right)^{2}},
$$

where $N$ is the number of PoIs, the subscripts $\mathrm{f}$ and $\mathrm{o}$ represent the forecasted and observed tsunami waveforms, respectively. $H^{\max }$ is the maximum amplitude of the tsunami, and $H^{\text {arr }}$ is the first-peak amplitude. A $K$ value closer to 1 indicates a better forecast. We multiplied the results of Eq. (4) with 100 to obtain percentage of forecast accuracy.

\section{Results and discussion}

Results of TDA for the May 2003 tsunami are given in Figs. 6 and 7 for the scenarios of 10, 5, 3 and 2 OBPGs. The forecast accuracy analysis is based on the comparison of the TDA-forecasted waveforms with observation (blue columns in Fig. 8) and simulations (orange columns in Fig. 8). It can be seen that the assimilated waveforms (red) match fairly well with the first tsunami cycle of the observations (black) in all four scenarios. Although the agreement is generally well in terms of wave period, the assimilated waveform in Sant Antoni arrives $\sim 10 \mathrm{~min}$ earlier than the observation. We attribute this travel time difference to the location of the Sant Antoni tide gauge station, which is inside the semi-enclosed bay with irregular coastal geometry and shallow bathymetry that significantly affect the tsunami travel time. A high-resolution bathymetry with a spatial resolution of at least $50 \mathrm{~m}$ is required to more accurately model the tsunami travel time to Sant Antoni. We also note that the relatively 


\section{a Input Waveforms of Designed OBPGs}

\section{Assimilation}
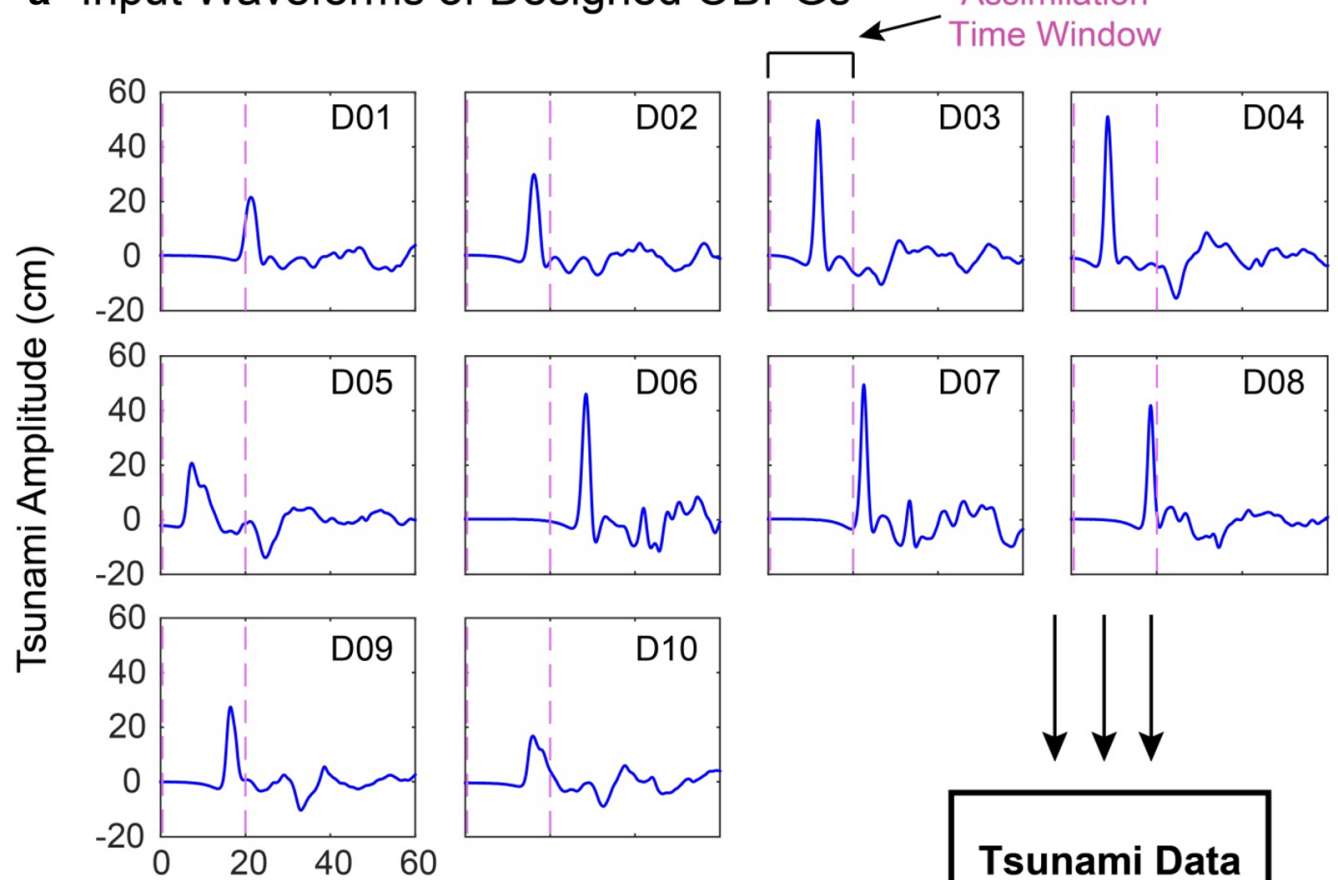

Time after quake origin time $(\mathrm{min})$

Tsunami Data Assimilation

\section{b Assimilated forecast of tide gauge records}

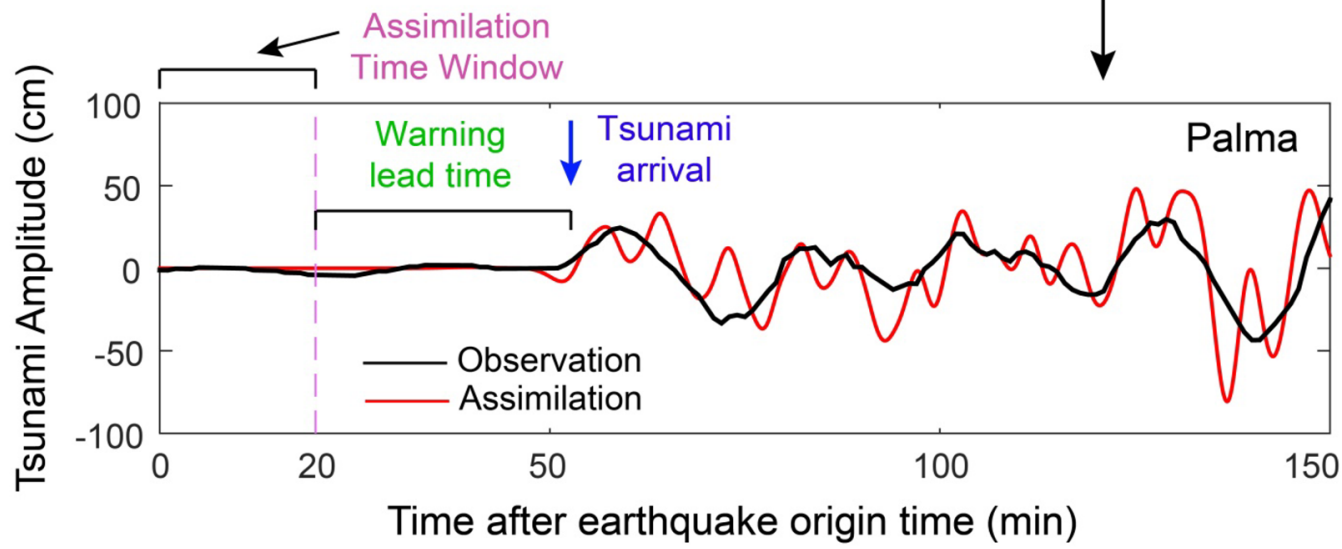

Fig. 5 Tsunami data assimilation process employing 20-min tsunami observation data from the OBPGs (a) and the forecasted tsunami in Palma using the tsunami data assimilation method (b)

smooth waveforms of the observations is due to the low sampling rates of 5 and 2 min while our simulations and assimilations possess temporal intervals of $1 \mathrm{~s}$. The third and fourth scenarios ( 3 and 2 OBPGs) appear to underestimate the first and second large peaks in Sant Antoni although they give acceptable estimations in other three PoIs.
Figure 8 presents the overall forecast accuracy for each of the four TDA scenarios by comparing the assimilated waveforms with both observations and simulations. The comparison with simulations gives better accuracies than with observations; we discuss here the forecast accuracies based on the comparison of the assimilated and observed waveforms. As expected, the first and the fourth scenarios yield the best and the worst performances, with 


\section{a First scenario (10 OBPGs)}
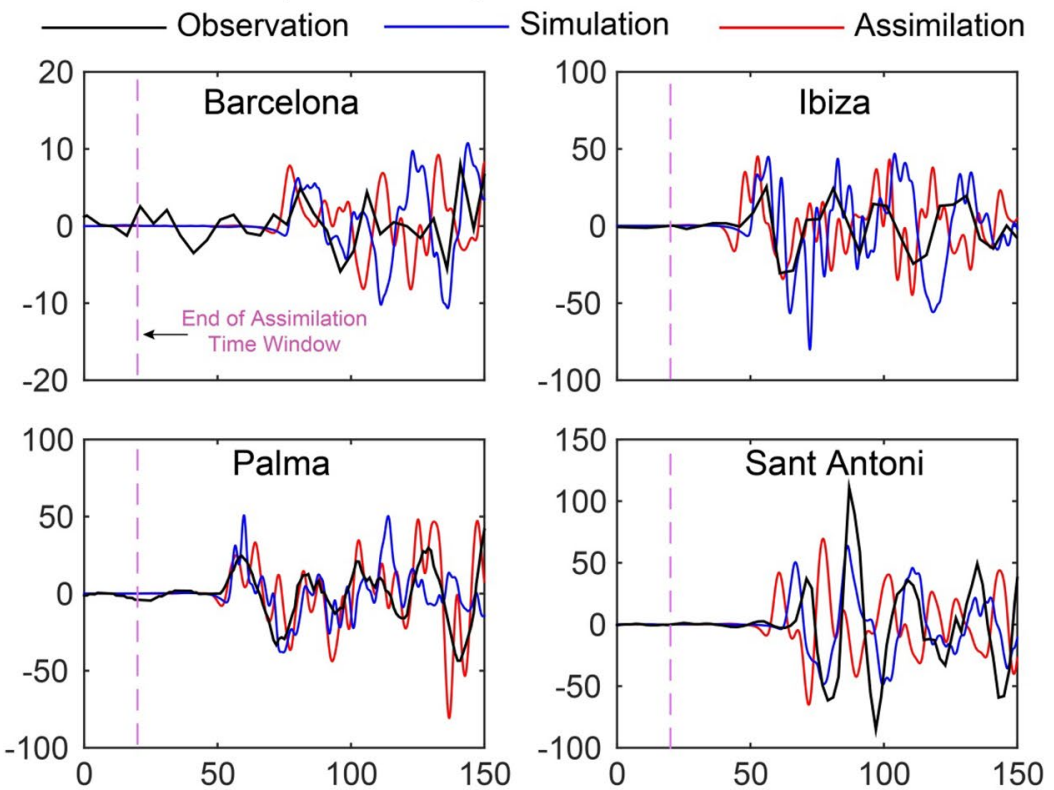

\section{b Second scenario (5 OBPGs)}

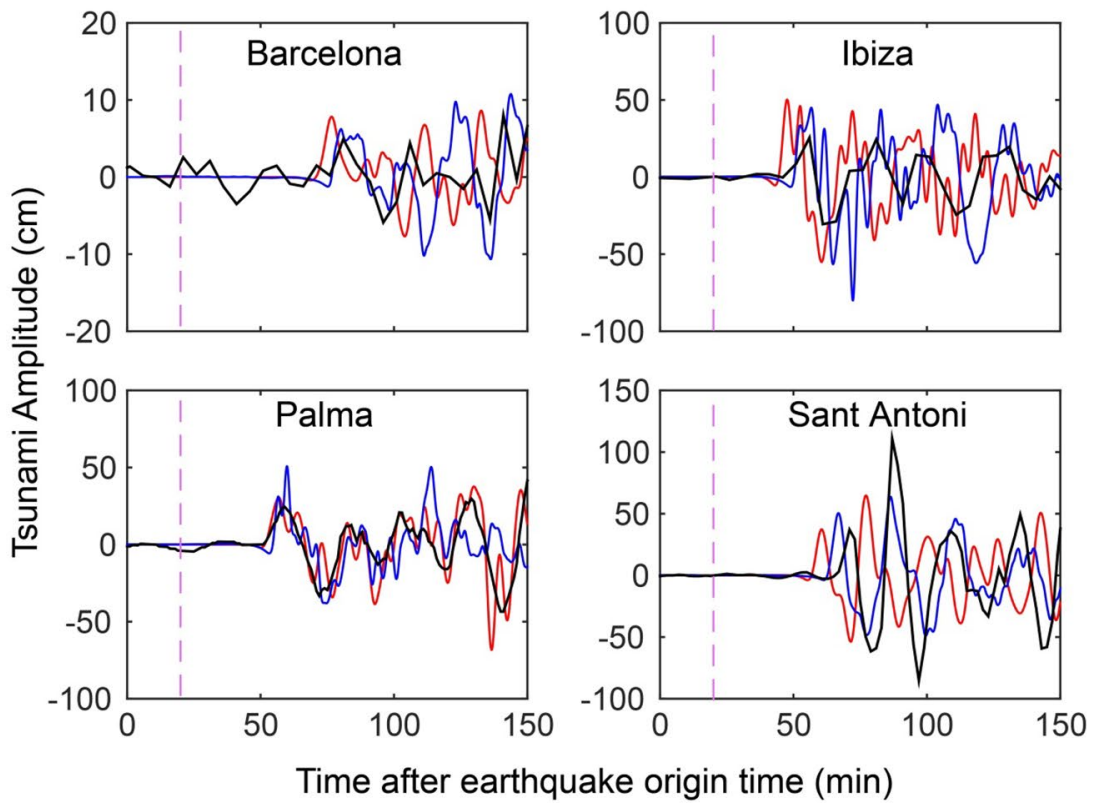

Fig. 6 Comparison of the observations (black lines), simulation (blue lines) and forecasted (data assimilation; red lines) waveforms at four Pols for the first (a; 10 OBPGs) and second (b; five OBPGs) scenarios. The time window for assimilation is $20 \mathrm{~min}$ (dashed vertical line)

forecast accuracies of $85 \%$ and $69 \%$, respectively. Since we used a time window of $20 \mathrm{~min}$ for assimilation and given the TTTs shown in Figs. 2, 3, the tsunami warning lead times for Ibiza, Palma, Sant Antoni and Barcelona are 20, 30, 48 and $55 \mathrm{~min}$, respectively. These lead times are sufficient to allow for effective tsunami warnings in all of these PoIs. We conclude that all of the four OBPG scenarios result in satisfactory performances towards forecasting the May 2003 tsunami. This indicates that deployment of OBPGs is beneficial for the tsunami warning system in the WMB.

The success of all four scenarios involving 2-10 OBPGs in forecasting of the May 2003 tsunami could be attributed to the relatively small size of the tsunami source 


\section{a Third scenario (3 OBPGs)}
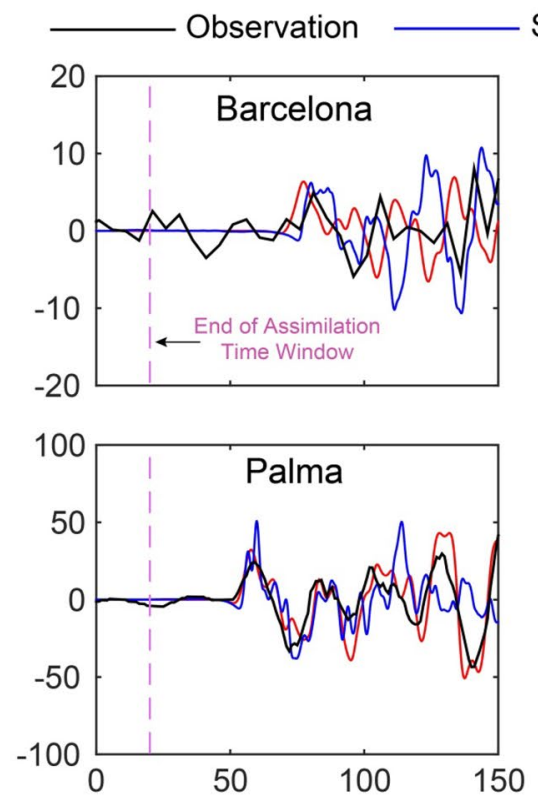

b Fourth scenario (2 OBPGs)

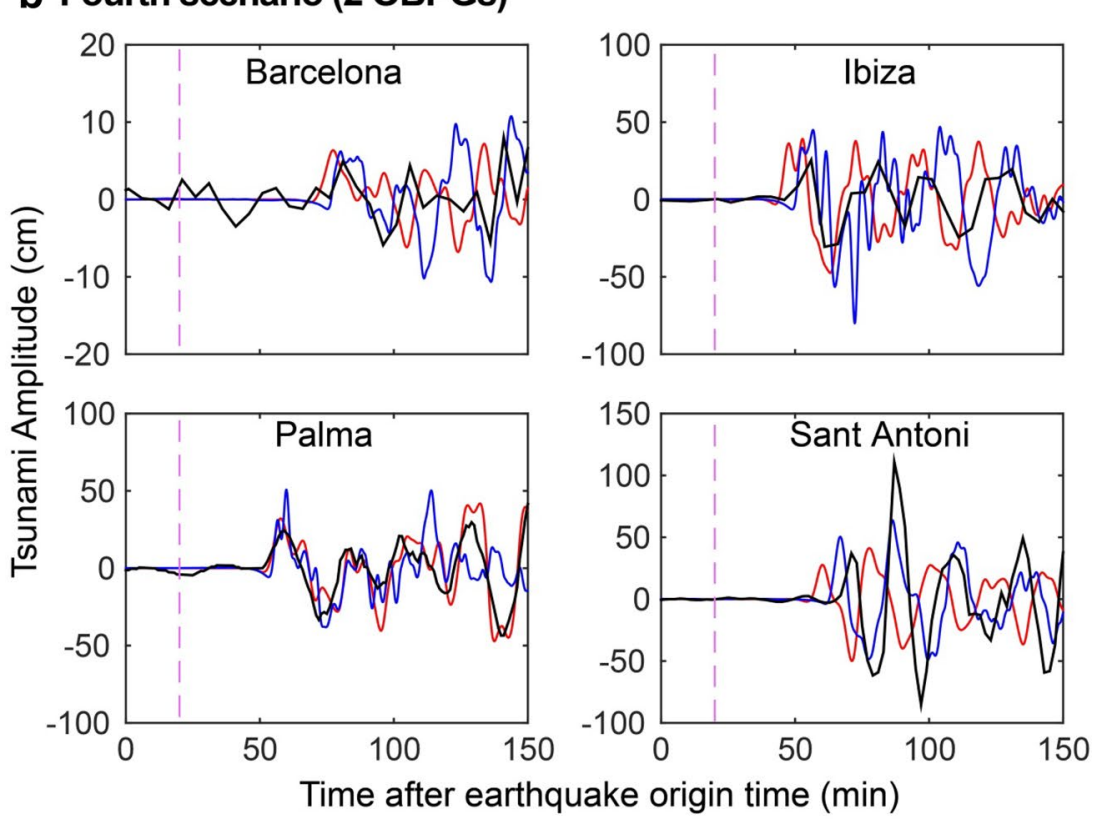

Fig. 7 Comparison of the observations (black lines), simulation (blue lines) and forecasted (data assimilation; red lines) waveforms at four Pols for the third (a; three OBPGs) and fourth (b; two OBPGs) scenarios. The time window for assimilation is 20 min (dashed vertical line)

( $70 \mathrm{~km}$; Fig. 3c), the SW-NE strike of the tsunamigenic fault (Fig. 3c), as well as the short distances of the OBPGs to the tsunami source area. The two OBPGs in scenario 4 can efficiently capture most of the May 2003 tsunami characteristics because they are spaced $100 \mathrm{~km}$ from each other, are aligned E-W and are located at the distance of $120-170 \mathrm{~km}$ from the epicenter. However, this
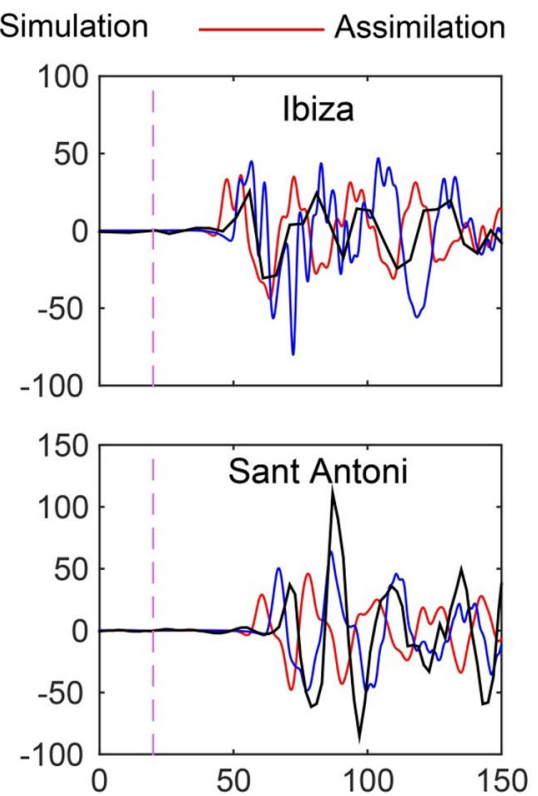

may not indicate that the scenario 4 (involving two OBPGs) will give the same forecast accuracy for other tsunamis with different sizes and strike angles. Our experience (Wang et al. 2019) showed that the larger the tsunami size and wavelength, the more OBPGs is required for accurate TDA. Clearly, detailed sensitivity analyses considering various earthquake scenarios (magnitude, 


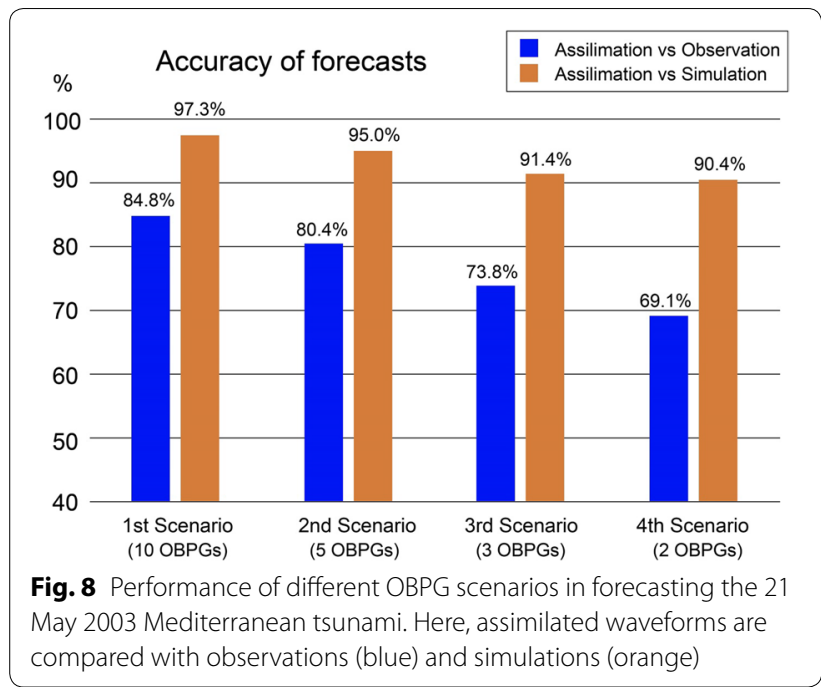

strike, epicenter) combined with numerous OBPGs arrangements (number, alignment, spacing) (Mulia et al. $2017,2019)$ are necessary to determine the optimum OBPGs network design for the WMB which can address tsunami threats from all four tsunamigenic zones in this basin. This was out of the scope of this study because we here focused on a single case study considering one tsunamigenic zone (i.e., NAC) and one real tsunami event (i.e., the May 2003 tsunami). Nonetheless, this study has demonstrated that using a considerably less number of OBPGs compared to that of the S-net and DONET systems in Japan, TDA can produce reasonable tsunami forecasts to enhance the tsunami warning system in the WMB. We note that the sufficiency of a forecast accuracy for a particular region is usually decided by the Civil Protection Authorities (CPA) and warning center guidelines; this is normally a function of the characteristics of the tsunamigenic zones and their distances to population centers.

\section{Conclusions}

We conducted a case study of tsunami data assimilation (TDA) for the Western Mediterranean Basin (WMB) considering one of the tsunamigenic zones in this basin namely the North African Coast (NAC) and a real tsunami event in this zone (i.e., the May 2003 event). The objective of this research was to study whether deployment of offshore bottom pressure gauges (OBPGs) combined with TDA could be satisfactorily applied for tsunami warning system in the WMB. Four scenarios of OBPG arrangements involving 10, 5, 3 and 2 gauges were considered with distances of $120-300 \mathrm{~km}$ from the NAC. An assimilation window time of $20 \mathrm{~min}$, from the earthquake origin time, was considered. Results showed that all four scenarios satisfactorily forecasted the May 2003 tsunami with forecast accuracies in the range of $69-85 \%$ and allowing warning lead times of 20, 30, 48 and $55 \mathrm{~min}$ for Ibiza, Palma, Sant Antoni and Barcelona, respectively. We conclude that deployment of OBPGs is beneficial for the tsunami warning system in the WMB. We note that our proposed OBPG arrangements are applicable only for the case of the May 2003 tsunami in the NAC. Detailed sensitivity analyses are required to propose OBPG designs that could be useful for various earthquake scenarios in the WMB.

\section{Abbreviations}

WMB: Western Mediterranean Basin; OBPGs: offshore bottom pressure gauges; TDA: tsunami data assimilation; COS: coast of Spain; NAC: North African Coast; LS: Ligurian Sea; WCITS: west coast of Italy and Tyrrhenian Sea; NEAMTWS: North East Atlantic, Mediterranean and Connected seas Tsunami Warning System; ICG/NEAMTWS: Intergovernmental Coordination Group for the Tsunami Early Warning and Mitigation System in the North-eastern Atlantic; INGV: Istituto Nazionale di Geofisica e Vulcanologia (Italy); KOERI: Kandilli Observatory and Earthquake Research Institute (Turkey); NOA: National Observatory of Athens (Greece); TSPs: Tsunami Service Providers; DART: Deep-Ocean Assessment and Reporting of Tsunamis; S-net: Seafloor Observation Network for Earthquakes and Tsunamis; DONET: Dense Ocean-floor Network System for Earthquakes and Tsunamis; TTT: tsunami travel time; TUNAMl: Tohoku University's Numerical Analysis Model for Investigation of Near-field tsunamis.

\section{Acknowledgements}

The tsunami observation records, used in this study, are provided by UNESCO/ IOC (Intergovernmental Oceanographic Commission), Puertos del Estado (Spain) (http://www.puertos.es/) and the European Sea Level Service (https:// www.bodc.ac.uk/projects/data_management/european/eseas/). The authors would also like to thank these organizations for making the data available to us. The GMT (Generic Mapping Tool) software (Wessel and Smith 1998) was used for drafting most of the figures.

\section{Authors' contributions}

$\mathrm{MH}$ initiated the idea of this research and prepared the initial draft, conducted forward tsunami simulations and produced relevant figures and texts. YW conducted the tsunami data assimilations (TDA), wrote the data and methods relevant to TDA, produced figures relevant to TDA and contributed to "Results" and "Conclusions". KS provided critical insights on the performance of TDA in the Mediterranean Sea, contributed to the structure of the article and wrote parts of "Results" and "Conclusions". IEM contributed to the TDA analysis, optimization of the locations of offshore gauges in the Mediterranean Sea and contributed to the write-up of the manuscript. All authors read and approved the final manuscript.

\section{Funding}

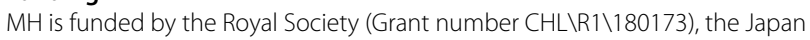
Society for the Promotion of Science (JSPS) (Grant number JSPS/IP/19003), and The Great Britain Sasakawa Foundation (Grant number 5542). YW's work was supported by JSPS KAKENHI Grant number JP19J20293.

\section{Availability of data and materials}

The sea level data used in this study come from the UNESCO/IOC (Intergovernmental Oceanographic Commission: http://www.ioc-sealevelmonitoring. org), the European Sea Level Service (http://www.eseas.org), and Puertos del Estado (Spain) (http://www.puertos.es/). The data are available in the aforesaid websites.

\section{Competing interests}

The authors declare that they have no competing interests. 


\section{Author details}

${ }^{1}$ Department of Civil \& Environmental Engineering, Brunel University London, Uxbridge UB8 3PH, UK. ${ }^{2}$ Earthquake Research Institute, The University of Tokyo, Tokyo 113-0032, Japan.

Received: 16 September 2019 Accepted: 3 December 2019 Published online: 16 December 2019

\section{References}

Alasset PJ, Hébert H, Maouche S, Calbini V, Meghraoui M (2006) The tsunami induced by the 2003 Zemmouri earthquake ( $M w=6.9$, Algeria): modelling and results. Geophys J Int 166:213-226

Déverchère J, Yelles K, Domzig A, Mercier de Lépinay B, Bouillin JP, Gaullier V, Bracène R, Calais E, Savoye B, Kherroubi A, Le Roy P (2005) Active thrust faulting offshore Boumerdes, Algeria, and its relations to the 2003 Mw 6.9 earthquake. Geophys Res Lett 32:4

Dogan GG, Annunziato A, Papadopoulos GA, Guler HG, Yalciner AC, Cakir TE, Sozdinler CO, Ulutas E, Arikawa T, Suzen ML, Guler I (2019) The 20th July 2017 Bodrum-Kos tsunami field survey. Pure Appl Geophys 176:2925-2949

Eva C, Rabinovich AB (1997) The February 23, 1887 tsunami recorded on the Ligurian coast, western Mediterranean. Geophys Res Lett 24(17):2211-2214

Geoware (2011) The tsunami travel times (TTT). http://www.geoware-onlin e.com/tsunami.html. Accessed Dec 2013

Gonzalez Fl, Milburn HM, Bernard EN, Newman JC (1998) Deep-ocean assessment and reporting of tsunamis (DART $\left.{ }^{\circledR}\right)$ : brief overview and status report. In: Proceedings of the international workshop on tsunami disaster mitigation, Tokyo, Japan, 19-22 January 1998

Goto C, Ogawa Y, Shuto N, Imamura F (1997) Numerical method of tsunami simulation with the leap-frog scheme (IUGG/IOC Time Project). IOC Manual, UNESCO, No 35

Gusman AR, Sheehan AF, Satake K, Heidarzadeh M, Mulia IE, Maeda T (2016) Tsunami data assimilation of Cascadia seafloor pressure gauge records from the 2012 Haida Gwaii earthquake. Geophys Res Lett 43(9):4189-4196

Heidarzadeh M, Gusman AR (2018) Application of dense offshore tsunami observations from Ocean Bottom Pressure Gauges (OBPGs) for tsunami research and early warnings. In: Durrani TS, Wang W, Forbes SM (eds) Geological disaster monitoring based on sensor networks. Springer, Berlin, pp 7-22. https://doi.org/10.1007/978-981-13-0992-2_2

Heidarzadeh M, Satake K (2013) The 21 May 2003 tsunami in the Western Mediterranean Sea: statistical and wavelet analyses. Pure Appl Geophys 170(9):1449-1462

Heidarzadeh M, Satake K, Murotani S, Gusman AR, Watada S (2015) Deepwater characteristics of the trans-pacific Tsunami from the 1 April 2014 M w 8.2 Iquique, Chile Earthquake. Pure Appl Geophys 172(3):719-730

Heidarzadeh M, Harada T, Satake K, Ishibe T, Gusman AR (2016) Comparative study of two tsunamigenic earthquakes in the Solomon Islands: $2015 \mathrm{MW}$ 7.0 normal-fault and 2013 Santa Cruz Mw 8.0 megathrust earthquakes. Geophys Res Lett 43(9):4340-4349

Heidarzadeh M, Necmioglu O, Ishibe T, Yalciner AC (2017) Bodrum-Kos (Turkey-Greece) Mw 6.6 earthquake and tsunami of 20 July 2017: a test for the Mediterranean tsunami warning system. Geosci Lett 4:31

IOC (Intergovernmental Oceanographic Commission, UNESCO) (2015) 10 years of the North-Eastern Atlantic, the Mediterranean and Connected Seas Tsunami Warning and Mitigation System (NEAMTWS): accomplishments and challenges in preparing for the next tsunami. 59 pages. https ://unesdoc.unesco.org/ark:/48223/pf0000247393

Kalnay E (2003) Atmospheric modeling, data assimilation and predictability. Cambridge University Press, Cambridge

Kanazawa T (2013) Japan trench earthquake and tsunami monitoring network of cable-linked 150 ocean bottom observatories and its impact to Earth disaster science. In: Underwater technology symposium (UT), 2013 IEEE international. Tokyo: IEEE; pp 1-5. https://doi.org/10.1109/UT.2013.65199 11

Kaneda Y, Hirahara K, Furumura T (2009) New research project for evaluating seismic linkage around the Nankai trough-integration of observation, simulation, and disaster mitigation. J Disaster Res 4(2):61-66
Kaneda Y, Kawaguchi K, Araki E, Matsumoto H, Nakamura T, Kamiya S, Ariyoshi K, Hori T, Baba T, Takahashi N (2015) Development and application of an advanced ocean floor network system for megathrust earthquakes and tsunamis. In: Favali P, Beranzoli L, De Santis A (eds) Seafloor observatories. Springer, Berlin, pp 643-662. https://doi.org/10.1007/978-3-642-11374 $-1 \_25$

Larroque C, Scotti O, loualalen M (2012) Reappraisal of the 1887 Ligurian earthquake (western Mediterranean) from macroseismicity, active tectonics and tsunami modelling. Geophys J Int 190(1):87-104

Maeda T, Obara K, Shinohara M, Kanazawa T, Uehira K (2015) Successive estimation of a tsunami wavefield without earthquake source data: a data assimilation approach toward real-time tsunami forecasting. Geophys Res Lett 42(19):7923-7932

Meghraoui M, Maouche S, Chemaa B, Cakir Z, Aoudia A, Harbi A, Alasset PJ, Ayadi A, Bouhadad Y, Benhamouda F (2004) Coastal uplift and thrust faulting associated with the $\mathrm{Mw}=6.8$ Zemmouri (Algeria) earthquake of 21 May, 2003. Geophys Res Lett. https://doi.org/10.1029/2004GL020466

Mulia IE, Gusman AR, Satake K (2017) Optimal design for placements of tsunami observing systems to accurately characterize the inducing earthquake. Geophys Res Lett 44:12106-12115

Mulia IE, Gusman AR, Williamson AL, Satake K (2019) An optimized array configuration of tsunami observation network off Southern Java, Indonesia. J Geophys Res. https://doi.org/10.1029/2019JB017600

Necmioğlu Ö (2016) Design and challenges for a tsunami early warning system in the Marmara Sea. Earth Planets Space 68:13

Necmioglu O, Özel NM (2015) Earthquake scenario-based tsunami wave heights in the Eastern Mediterranean and connected seas. Pure Appl Geophys 172(12):3617-3638

Okada Y (1985) Surface deformation due to shear and tensile faults in a halfspace. Bul Seismol Soc Am 75:1135-1154

Okal EA, Synolakis CE, Uslu B, Kalligeris N, Voukouvalas E (2009) The 1956 earthquake and tsunami in Amorgos, Greece. Geophys J Int 178(3):1533-1554

Öztürk S, Şahin \$̧ (2019) A statistical space-time-magnitude analysis on the aftershocks occurrence of the July 21th, $2017 \mathrm{MW}=6.5$ Bodrum-Kos, Turkey, earthquake. J Asian Earth Sci 172:443-457

Papadopoulos GA (2015) Tsunamis in the European-Mediterranean Region: from historical record to risk mitigation. Elsevier, Amsterdam, p 290. ISBN 978-0-12-420224-5

Papadopoulos GA, Fokaefs A (2013) Near-field tsunami early warning and emergency planning in the Mediterranean Sea. Res Geophys 3:24-31

Rabinovich AB, Eblé MC (2015) Deep-ocean measurements of tsunami waves. Pure Appl Geophys 172:3281-3312

Roger J, Hébert H (2008) The 1856 Djijelli (Algeria) earthquake and tsunami: source parameters and implications for tsunami hazard in the Balearic Islands. Nat Hazards Earth Syst Sci 8(4):721-731

Sahal A, Roger J, Allgeyer S, Lemaire B, Hébert H, Schindelé F, Lavigne F (2009) The tsunami triggered by the 21 May 2003 Boumerdes-Zemmouri (Algeria) earthquake: field investigations on the French Mediterranean coast and tsunami modelling. Nat Hazards Earth Syst Sci 9(6):1823

Satake K (2014) Advances in earthquake and tsunami sciences and disaster risk reduction since the 2004 Indian ocean tsunami. Geosci Lett 1(1):15

Soloviev SL (1990) Tsunamigenic zones in the Mediterranean Sea. Nat Hazards 3:183-202

Synolakis CE, Bernard EN (2006) Tsunami science before and beyond Boxing Day 2004. Philos Trans R Soc Lond A 364(1845):2231-2265

Tinti S, Graziani L, Brizuela B, Maramai A, Gallazzi S (2012) Applicability of the decision matrix of North Eastern Atlantic, Mediterranean and connected seas Tsunami Warning System to the Italian tsunamis. Nat Hazards Earth Syst Sci 12:843-857

Tsushima H, Hino R, Fujimoto H, Tanioka Y, Imamura F (2009) Near-field tsunami forecasting from cabled ocean bottom pressure data. J Geophys Res Solid Earth 114:B06309. https://doi.org/10.1029/2008JB005988

Wang Y, Satake K, Maeda T, Gusman AR (2017) Green's function-based tsunami data assimilation: a fast data assimilation approach toward tsunami early warning. Geophys Res Lett 44(20):10-282

Wang Y, Satake K, Maeda T, Gusman AR (2018) Data assimilation with dispersive tsunami model: a test for the Nankai Trough. Earth Planets Space 70(1):131

Wang Y, Maeda T, Satake K, Heidarzadeh M, Su H, Sheehan AF, Gusman AR (2019) Tsunami data assimilation without a dense observation network. Geophys Res Lett 46(4):2045-2053 
Weatherall P, Marks KM, Jakobsson M, Schmitt T, Tani S, Arndt JE, Rovere M, Chayes D, Ferrini V, Wigley R (2015) A new digital bathymetric model of the world's oceans. Earth Space Sci 2:331-345

Wessel P, Smith WHF (1998) New, improved version of generic mapping tools released. EOS Trans AGU 79(47):579

Yalçiner A, Pelinovsky E, Talipova T, Kurkin A, Kozelkov A, Zaitsev A (2004) Tsunamis in the Black Sea: comparison of the historical, instrumental, and numerical data. J Geophys Res. https://doi.org/10.1029/2003JC002113 Yamamoto N, Aoi S, Hirata K, Suzuki W, Kunugi T, Nakamura H (2016) Multiindex method using offshore ocean-bottom pressure data for real-time tsunami forecast. Earth Planets Space 68(1):128
Yang Y, Dunham EM, Barnier G, Almquist M (2019) Tsunami wavefield reconstruction and forecasting using the ensemble Kalman Filter. Geophys Res Lett 46:853-860

\section{Publisher's Note}

Springer Nature remains neutral with regard to jurisdictional claims in published maps and institutional affiliations.

\section{Submit your manuscript to a SpringerOpen ${ }^{\circ}$ journal and benefit from:}

- Convenient online submission

- Rigorous peer review

- Open access: articles freely available online

- High visibility within the field

Retaining the copyright to your article

Submit your next manuscript at $>$ springeropen.com 